13

\title{
Параметры активности нано- и микропорошков железа и алюминия при окислении в воздухе после СВЧ облучения
}

\author{
(C) А.В. Мостовщиков, А.П. Ильин, П.Ю. Чумерин, Ю.Г. Юшков \\ Томский политехнический университет, \\ 634050 Томск, Россия \\ e-mail: pasembellum@mail.ru
}

(Поступило в Редакцию 7 декабря 2017 г.)

\begin{abstract}
Изучены облученные нанопорошок железа, микропорошки железа и алюминия СВЧ излучением с частотой $9.4 \mathrm{GHz}$ и плотностью мощности $80 \mathrm{~W} / \mathrm{cm}^{2}$, частота следования импульсов составила $400 \mathrm{~Hz}$. Согласно результатам дифференциального термического анализа, воздействие СВЧ излучения привело к немонотонным изменениям термических свойств порошков $\mathrm{Al}$ и $\mathrm{Fe}$. После облучения нанопорошка железа температура начала его окисления возрастала от 150.01 до $158.75^{\circ} \mathrm{C}$, а для микронного - немонотонно изменялась в диапазоне от 150.00 до $275.38^{\circ} \mathrm{C}$. Удельный тепловой эффект окисления нанопорошка $\mathrm{Fe}$ максимально увеличился на $17.3 \%$, в то время как максимально достигнутое увеличение для микронного порошка $\mathrm{Fe}$ составило 13\%. Для микронного порошка $\mathrm{Al}$ установлено повышение удельного теплового эффекта окисления максимально на 59.7\%. При действии СВЧ излучения сформированы лавины электронов, которые восстанавливают ионы металлов в их оксидах. В то же время генерируемые потоки электронов при определенных дозах облучения окисляли восстановленные металлы, что и проявляется в виде немонотонного изменения свойств. Повышение удельного теплового эффекта связано с участием энергонасыщенных состояний металлов в процессах окисления.
\end{abstract}

DOI: $10.21883 /$ JTF.2018.08.46318.2590

\section{Введение}

Наноразмерные и микронные порошки металлов находят все большее применение в различных технологиях. Сочетание таких факторов, как высокая площадь удельной поверхности, высокая (в сравнении с массивным состоянием) скорость и теплота окисления, позволяют использовать порошки в составе высокоэнергетических материалов [1], в порошковой металлургии, составах для спекания керамик, 3D-печати и т.д. [2]. Ранее было показано, что различные высокоэнергетические воздействия на наноматериалы изменяют их свойства $[3,4]$. В частности, известно, что воздействие электронных пучков приводит к восстановлению окисленного графита [5]. Известно, что воздействие потоков ускоренных электронов существенно меняет микроструктурные и термохимические свойства порошков металлов. Например, воздействие электронных пучков с энергией $4.0 \mathrm{MeV}$ на нанопорошки железа привело к увеличению теплового эффекта окисления в 2.3 раза [6].

Электромагнитное излучение сверхвысокой частоты также находит все большее применение в различных технологиях, вследствие чего активно развивается исследование механизмов взаимодействия СВЧ излучения с веществом [7,8]. В настоящее время начинает активно развиваться направление модифицирования физико-химических свойств порошков металлов с помощью СВЧ излучения. В частности, ранее установлено, что воздействие СВЧ излучения на нанопорошок алюминия приводит к снижению температуры начала окисления порошка, повышению удельного теплового эффекта окисления, а также к увеличению степени окисленности при нагревании в воздухе [9]. К сожалению, влияние СВЧ излучения на микронные порошки алюминия оставалось не изученным, несмотря на то, что микронные и наноразмерные порошки алюминия находят все большее применение [2]. Учитывая также широкое распространение порошков железа в промышленности, актуальным и неизученным остается воздействие СВЧ излучения на нано- и микронные порошки железа. Таким образом, целью настоящей работы являлось определение зависимости параметров термической активности микронных порошков алюминия, а также нано- и микропорошков железа от энергии СВЧ излучения.

\section{Характеристики объектов исследования}

В настоящей работе исследованы нанопорошок железа, полученный в условиях электрического взрыва проводника в среде аргона [2], а также микронный порошок железа марки R-10 [10] и микронный порошок алюминия марки ASD-10. Среднеповерхностный диаметр частиц микронного порошка алюминия составлял $3 \mu \mathrm{m}$, площадь удельной поверхности $0.8 \mathrm{~m}^{2} / \mathrm{g}$. Нанопорошок железа имел среднеповерхностный диаметр частиц $110 \mathrm{~nm}$ и площадь удельной поверхности $7.1 \mathrm{~m}^{2} / \mathrm{g}$, а микронный порошок - $4 \mu \mathrm{m}$ и $0.2 \mathrm{~m}^{2} / \mathrm{g}$ соответственно. Все порошки были слабо агломерированными, содержание металлического железа составляло не менее 96 wt.\% в нанопорошке и 98.5 wt.\% в микронном порошке. Все 


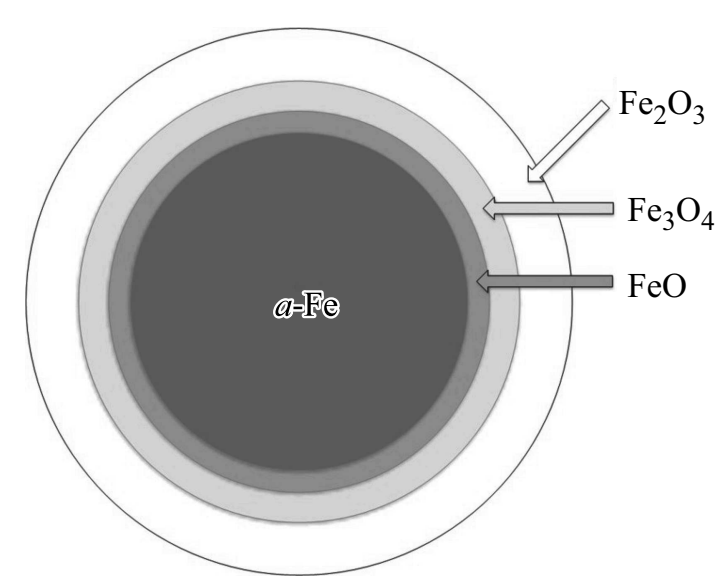

Pис. 1. Схема строения частицы порошка железа.

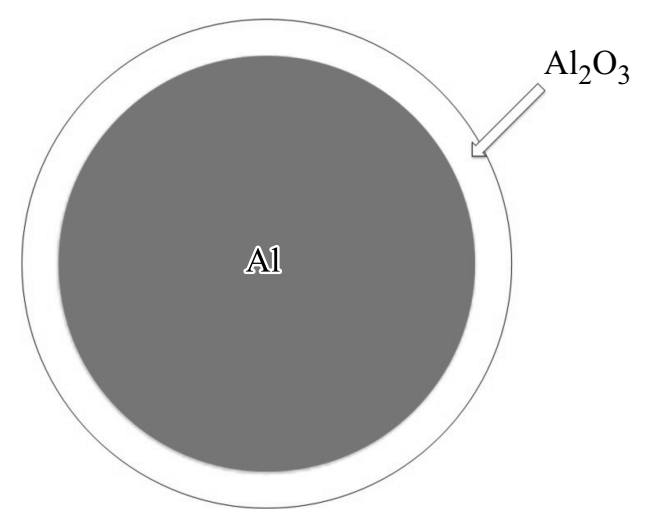

Pис. 2. Схема строения частицы порошка алюминия.

частицы и нано- и микронного порошков $\mathrm{Al}$ и $\mathrm{Fe} \mathrm{c}$ поверхности покрыты оксидной оболочкой (рис. 1,2).

\section{Методики экспериментов}

Облучение порошков алюминия и железа выполняли в безэховой камере с применением установки и методики, ранее описанной авторами в работе [9]. Упрощенная схема проведения экспериментов показана на рис. 3. Облучение проводили в атмосфере воздуха СВЧ излучением с частотой $9.4 \mathrm{GHz}$ и плотностью мощности $80 \mathrm{~W} / \mathrm{cm}^{2}$, частота следования импульсов составляла $400 \mathrm{~Hz}$.

Исследование влияния СВЧ излучения на порошки металлов проводили с помощью дифференциального термического анализа [11] с использованием термоанализатора SDT Q 600. Точность измерения температуры, согласно паспорту прибора, составляла $0.001^{\circ} \mathrm{C}$, удельного теплового эффекта $\pm 1.8 \%$. Результаты исследований приведены в табл. 1 (микронный порошок Al), 2 (нанопорошок $\mathrm{Fe}$ ) и 3 (микронный порошок $\mathrm{Fe}$ ). Детальное исследование закономерностей воздействия СВЧ излучения на изменение свойств нанопорошка алюминия авторами настоящей статьи было изучено ранее [9].

\section{Экспериментальные результаты}

Изменение параметров термической активности порошка ASD-10 после воздействия СВЧ излучения приведено в табл. 1.

Согласно данным табл. 1, при облучении микронного порошка алюминия увеличиваются удельный тепловой эффект окисления порошка и степень окисленности. В проведенной серии экспериментов максимальное значение степени окисленности составляло $91.6 \mathrm{wt} . \%$ для образца 10 (табл. 1). Температура начала окисления изменялась немонотонно: для образца 8 зафиксировано ее максимальное увеличение до $529.28^{\circ} \mathrm{C}$ (на $6.8 \%$ по абсолютной термодинамической температурной шкале Кельвина) и уменьшение до $400.31^{\circ} \mathrm{C}$ (на $10.2 \%$ ) для образца 6. Суммарный удельный тепловой эффект в проведенных экспериментах максимально увеличивался на $59.7 \%$ для образца 10. Таким образом, воздействие потоков импульсного высокоэнергетического СВЧ излучения на микронный порошок алюминия приводило к увеличению его теплового эффекта окисления, т.е. происходило активирование порошка. Согласно данным, полученным в предыдущей работе авторов [9, табл., образцы 0 и 1], для нанопорошка алюминия при действии СВЧ излучения также характерно увеличение удельного теплового эффекта окисления (максимально на $\sim 35.1 \%$ ) и немонотонное изменение температуры начала окисления нанопорошка алюминия.

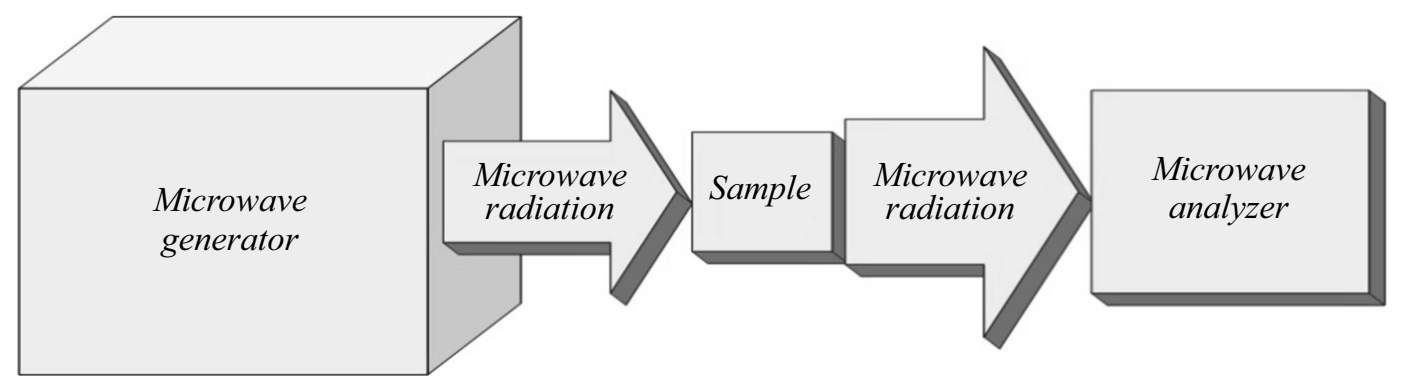

Рис. 3. Схема облучения образцов порошков. 
Таблица 1. Параметры химической активности облученного порошка алюминия марки ASD-10

\begin{tabular}{|c|c|c|c|c|c|}
\hline № & $\begin{array}{c}\text { Время } \\
\text { облучения, } \\
\text { s }\end{array}$ & $\begin{array}{c}\text { Энергия } \\
\text { СВЧ } \\
\text { облучения, } \\
\text { J }\end{array}$ & $\begin{array}{c}\text { Температура } \\
\text { начала } \\
\text { окисления, } \\
{ }^{\circ} \mathrm{C}\end{array}$ & $\begin{array}{c}\text { Удельный } \\
\text { тепловой } \\
\text { эффект } \\
\text { окисления, J/g }\end{array}$ & $\begin{array}{c}\text { Степень } \\
\text { окисленности, } \\
\text { \% }\end{array}$ \\
\hline 0 & 0 & 0 & 477.64 & 9500 & 67.9 \\
\hline 1 & 4 & 7.2 & 466.77 & 12967 & 80.3 \\
\hline 2 & 8 & 14.4 & 459.42 & 13996 & 80.9 \\
\hline 3 & 12 & 21.6 & 487.98 & 14582 & 83.6 \\
\hline 4 & 16 & 28.8 & 432.16 & 13068 & 79.5 \\
\hline 5 & 20 & 36.0 & 492.34 & 13548 & 79.7 \\
\hline 6 & 24 & 43.2 & 400.31 & 13118 & 77.8 \\
\hline 7 & 28 & 50.4 & 476.26 & 15015 & 81.8 \\
\hline 8 & 32 & 57.6 & 529.28 & 12540 & 75.9 \\
\hline 9 & 36 & 64.8 & 439.31 & 14451 & 79.6 \\
\hline 10 & 40 & 72.0 & 461.97 & 15178 & 91.6 \\
\hline
\end{tabular}

Таблица 2. Параметры химической активности облученного СВЧ излучением электровзрывного нанопорошка железа

\begin{tabular}{c|c|c|c|c|c}
\hline № & $\begin{array}{c}\text { Время } \\
\text { облучения, } \\
\text { s }\end{array}$ & $\begin{array}{c}\text { Энергия } \\
\text { СВЧ } \\
\text { облучения, } \\
\mathrm{J}\end{array}$ & $\begin{array}{c}\text { Температура } \\
\text { начала } \\
\text { окисления, } \\
{ }^{\circ} \mathrm{C}\end{array}$ & $\begin{array}{c}\text { Удельный } \\
\text { тепловой } \\
\text { эффект } \\
\text { окисления, J/g }\end{array}$ & $\begin{array}{c}\text { Степень } \\
\text { окисленности, } \\
\%\end{array}$ \\
\hline 0 & 0 & 0 & 155.99 & 3635 & 40.9 \\
1 & 4 & 7.2 & 152.04 & 3668 & 39.6 \\
2 & 8 & 14.4 & 151.80 & 3388 & 37.7 \\
3 & 12 & 21.6 & 150.32 & 3688 & 37.3 \\
4 & 16 & 28.8 & 150.65 & 3350 & 39.9 \\
5 & 20 & 36.0 & 150.01 & 3085 & 33.3 \\
7 & 24 & 43.2 & 151.85 & 3802 & 34.5 \\
9 & 32 & 50.4 & 156.47 & 3264 & 32.0 \\
\end{tabular}

Таблица 3. Параметры химической активности облученного микронного порошка железа марки R-10

\begin{tabular}{|c|c|c|c|c|c|}
\hline № & $\begin{array}{c}\text { Время } \\
\text { облучения, } \\
\text { s }\end{array}$ & $\begin{array}{c}\text { Энергия } \\
\text { СВЧ } \\
\text { облучения, } \\
\text { J }\end{array}$ & $\begin{array}{c}\text { Температура } \\
\text { начала } \\
\text { окисления, } \\
{ }^{\circ} \mathrm{C}\end{array}$ & $\begin{array}{c}\text { Удельный } \\
\text { тепловой } \\
\text { эффект } \\
\text { окисления, J/g }\end{array}$ & $\begin{array}{c}\text { Степень } \\
\text { окисленности, } \\
\%\end{array}$ \\
\hline 0 & 0 & 0 & 204.88 & 6613 & 39.2 \\
\hline 1 & 4 & 7.2 & 252.66 & 6562 & 38.1 \\
\hline 2 & 8 & 14.4 & 275.38 & 6260 & 37.9 \\
\hline 3 & 12 & 21.6 & 179.23 & 6138 & 34.5 \\
\hline 4 & 16 & 28.8 & 159.74 & 6222 & 36.8 \\
\hline 5 & 20 & 36.0 & 200.93 & 6390 & 39.9 \\
\hline 6 & 24 & 43.2 & 150.02 & 6540 & 41.7 \\
\hline 7 & 28 & 50.4 & 223.55 & 6126 & 34.3 \\
\hline 8 & 32 & 57.6 & 248.21 & 7507 & 46.9 \\
\hline 9 & 36 & 64.8 & 198.02 & 5870 & 35.6 \\
\hline 10 & 40 & 72.0 & 150.00 & 7092 & 42.3 \\
\hline
\end{tabular}

Термохимические параметры электровзрывного нанопорошка железа после воздействия СВЧ излучения приведены в табл. 2.
Согласно данным табл. 2, с ростом дозы облучения значение температуры начала окисления после облучения изменялись в пределах от 150.01 до $158.75^{\circ} \mathrm{C}$, 
причем эти изменения носили колебательный характер. Величина удельного теплового эффекта изменялась от 3081 до $4264 \mathrm{~J} / \mathrm{g}$. Максимальное увеличение удельного теплового эффекта в сравнении с удельным тепловым эффектом окисления исходного нанопорошка железа составило $17.3 \%$. В то же время значение удельного теплового эффекта облученного нанопорошка железа снижалось минимально на $15.2 \%$.

В табл. 3 приведены параметры активности микронного порошка железа R-10 после СВЧ-воздействия.

Согласно данным табл. 3, каждый из параметров химической активности изменялся на значительную величину. Температура начала окисления после СВЧ воздействия максимально увеличивалась на $70.50^{\circ} \mathrm{C}$, а уменьшалась максимально на $54.88^{\circ} \mathrm{C}$. Удельный тепловой эффект окисления после действия СВЧ излучения изменялся в диапазоне от 5870 до $7507 \mathrm{~J} / \mathrm{g}$. Величина степени окисленности облученных порошков максимально различалась на $12.6 \%$. Согласно данным термического анализа, процесс окисления нанопорошка железа протекал в две стадии (в табл. 1 представлен суммарный удельный тепловой эффект двух стадий), в то же время микронный порошок окислялся в одну стадию.

Согласно данным табл. 2,3, после облучения порошков железа при монотонном увеличении введенной в образец дозы наблюдали колебания значений термохимических параметров активности. Подобные колебания ранее наблюдали после облучения монокристаллов галогенидов щелочных металлов электронными пучками [12]. В то же время такие ярко выраженные немонотонные изменения термохимических величин нехарактерны при облучении порошков железа электронными пучками при эквивалентных введенных в образцы дозах энергии [13].

\section{Заключение}

Известно, что воздействие СВЧ излучения [14,15], как и электронных пучков [16,17], на оксиды алюминия и железа в присутствии восстановителя приводит к восстановлению окисленных форм металлов в соответствующих оксидах. В случае микро- и нанопорошков алюминия и железа порошки представляют собой композит „металл-оксид“, покрытый слоем адсорбированной воды и кислорода. После диссоциации молекул воды и восстановления протонов в порошках присутствует некоторое количество водорода, который при воздействии СВЧ излучения способен ускорять восстановление $\mathrm{Al}$ и $\mathrm{Fe}$ из их оксидов.

Различие в закономерностях протекания процессов при нагревании после облучения, вероятно, связано с различным строением оксидных оболочек порошков алюминия и железа (рис. 1,2). Алюминий является парамагнитным веществом, и, кроме того, частицы алюминия покрыты оксидным слоем $\left(\mathrm{Al}_{2} \mathrm{O}_{3}\right)$, являющимся диамагнетиком [18] с диэлектрической проницаемостью 8, и который не может существенно ослаблять влияние СВЧ излучения [19]. Порошки железа покрыты оксидным слоем, содержащим в своем составе магнетит $\left(\mathrm{Fe}_{3} \mathrm{O}_{4}\right.$, рис. 1), который в наноразмерном состоянии проявляет себя как суперпарамагнетик [20]. Таким образом, оксидная оболочка на поверхности железа не может оказывать существенного экранирующего действия, препятствующего проникновению СВЧ излучения к металлической составляющей наночастицы.

Наиболее вероятным представляется следующий механизм воздействия СВЧ излучения на металлическую составляющую микро- и наночастиц алюминия и железа. Электромагнитное излучение СВЧ, использованное в настоящей работе, имеет напряженность электрического поля до $30 \mathrm{kV} / \mathrm{cm}$. Из-за малости размеров частиц и большой кривизны поверхности вблизи наночастиц напряженность поля может многократно усиливаться. Излучение, проникая внутрь микро- и наноразмерных частиц, вызывает ионизацию атомов алюминия (железа) и образование электронных лавин (внутренний фотоэффект). Образующиеся потоки электронов взаимодействуют с оксидной оболочкой на поверхности частиц. Это приводит к частичному восстановлению окисленных форм алюминия (железа) [21]. В результате такого восстановления возрастает удельный тепловой эффект окисления порошков из-за увеличения содержания металла в частице. С ростом дозы облучения происходит накопление восстановленных форм металла в оксидной оболочке и одновременно его ионизация и окисление. Следствием и проявлением этого процесса является колебание температуры начала окисления порошков при различных поглощенных дозах (табл. 1-3). Наиболее ярко эти эффекты (восстановление-окисление) выражены в порошках железа (табл. 2,3) вследствие слоистого строения их оксидной оболочки (рис. 1).

Кроме того, при возникновении электронных лавин в структуре наночастиц при действии импульсного СВЧ излучения после окончания импульса воздействия электроны, теряя свою кинетическую энергию, вероятно, могут внутри кристаллической решетки металлов и оксидных оболочек наночастиц восстанавливать ионы и образовывать включения нейтральных атомов. Этот процесс для порошков алюминия описывается следующими схемами:

$$
\begin{aligned}
& \mathrm{Al}^{3+}+\bar{e} \rightarrow \mathrm{Al}^{2+}+28.4 \mathrm{eV} \\
& \mathrm{Al}^{2+}+\bar{e} \rightarrow \mathrm{Al}^{+}+18.8 \mathrm{eV} \\
& \mathrm{Al}^{+}+\bar{e} \rightarrow \mathrm{Al}^{0}+5.9 \mathrm{eV}
\end{aligned}
$$

Таким образом, наиболее вероятной причиной увеличения удельного теплового эффекта окисления порошков алюминия является формирование энергонасыщенных состояний - образование кластеров $\mathrm{Al}^{3+}, \mathrm{Al}^{2+}, \mathrm{Al}^{+}$ в приповерхностном слое и нейтральных атомов $\mathrm{Al}^{0}$ в оксидной оболочке наночастицы. 
Для порошков железа процесс также описывается аналогичными схемами:

$$
\begin{gathered}
\mathrm{Fe}^{3+}+\bar{e} \rightarrow \mathrm{Fe}^{2+}+30.6 \mathrm{eV}, \\
\mathrm{Fe}^{2+}+\bar{e} \rightarrow \mathrm{Fe}^{+}+16.2 \mathrm{eV}, \\
\mathrm{Fe}^{+}+\bar{e} \rightarrow \mathrm{Fe}^{0}+8.2 \mathrm{eV} .
\end{gathered}
$$

Причиной изменения удельного теплового эффекта окисления порошков железа также является восстановление ионов железа в структуре оксидной оболочки частицы. Разброс величины удельного теплового эффекта для порошков железа больше, чем для порошков алюминия из-за различной структуры оксидных слоев на поверхности частиц. Для порошков железа, имеющих несколько оксидных слоев с различными степенями окисления железа при действии излучения, возможно механическое разрушение оксидных слоев и быстрое окисление металлической составляющей порошка уже в процессе облучения. При нагревании удельный тепловой эффект окисления облученных порошков железа уменьшается в сравнении с необлученным порошком $\mathrm{Fe}$ (табл. 2, 3).

Вероятной причиной колебаний температуры начала окисления порошков алюминия и железа является частичное восстановление ионов металлов в оксидной оболочке частиц и образование субоксидов. Повышение содержания восстановленного металла в оксидной пленке снижает температуру начала окисления нанопорошка при нагревании в воздухе. В то же время в процессе облучения в атмосфере воздуха в присутствии кислорода металл в оболочке наночастицы вновь окисляется, а также протекают процессы рекристаллизации. Это приводит к увеличению температуры начала окисления.

Работа выполнена при поддержке Государственного задания „Наука“, проект № 11.1928.2017/4.6, а также в рамках программы повышения конкурентоспособности российских вузов Минобрнауки РФ.

\section{Список литературы}

[1] Ellern H. Military and Civilian Pyrotechnics. Chemical Publisher, 1968.

[2] Gromov A.A., Teipel U. Metal Nanopowders: Production, Characterization, and Energetic Applications. Weinheim: Wiley-VCH, 2014.

[3] Андриевский Р.А. // УФН. 2014. Т. 184. № 10. C. $1017-1032$.

[4] Морохов И.Д., Петинов В.П., Трусов Л.И., Петрунин В.Ф. // УФН. 1981. Т. 133. № 4. С. 653-691.

[5] Микушкин В.М., Крюков А.С. // Письма в ЖТФ. 2016 Т. 42. Вып. 7. С. 1-9.

[6] Ильин А.П., Роот Л.О., Мостовщиков А.В. // ЖТФ. 2012. Т. 82. Вып. 8. С. 140-142. [Il'in A.P., Root L.O., Mostovshchikov A.V. // Technical Physics. 2012. Vol. 57. N 8. P. $1178-1180$.]

[7] Sun J., Wang W., Yue Q. // Materials. 2016. Vol. 9. P 231.
[8] Диденко А.Н. СВЧ-энергетика: Теория и практика. М.: Наука, 2003. 446 с.

[9] Мостовщиков А.В., Ильин А.П., Чумерин П.Ю., Юиков Ю.Г., Ваулин В.А., Алексеев Б.А. // Письма в ЖТФ. 2016. T. 42. Вып. 7. C. 17-22. [Mostovshchikov A.V., Il'in A.P., Chumerin P.Yu., Yushkov Yu.G., Vaulin V.A., Alekseev B.A. // Tech. Phys. Lett. 2016. Vol. 42. P. 344-346.]

[10] Сыркин В.Г. Карбонилы металлов. М.: Химия, 1983. 200 с.

[11] Wendlandt W.W. Thermal Methods of Analysis. N. Y.: John Wiley \& Sons, 1974.

[12] Борисовский В.В., Воробьев А.А., Головчанский Е.М., Завадовская E.К. // Известия Томского политех. ин-та. 1977. T. 247. C. 6-29.

[13] Mostovshchikov A.V., Ilyin A.P., Egorov I.S., Ismailov D.V. // Key Engineer. Mater. 2016. Vol. 712. P. 60-64.

[14] Brecelj F., Mozetic M. // Vacuum. 1990. Vol. 40. N 1-2. P. $177-178$.

[15] Standish N., Worner H. // J. Microwave Power and Electromagnetic Energy. 1990. Vol. 25. N 3. P. 177-180.

[16] Bonevich J.E., Marks L.D. Electron radiation damage of $\alpha$-alumina. 1991. Ultramicroscopy. Vol. 35. P. 161-166.

[17] Smith D.J., McCartney M.R., Bursill L.A. The electron-beaminduced reduction of metal oxide surfaces to metallic lower oxidation. 1987. Ultramicroscopy. Vol. 23. P. 299-304.

[18] Бардаханов С.П., Завьялов А.П., Зобов К.В. идр. // Вестник НГУ. Серия: Физика. 2009. Т. 4. Вып. 1. С. 75-79.

[19] Вакуумная СВЧ электроника: Сборник обзоров. Нижний Новгород: ИПФ РАН, 2002. $160 \mathrm{c}$.

[20] Никифоров В.Н., Игнатенко А.Н., Ирхин В.Ю. // Известия РАН. Серия физическая. 2014. Т. 78. № 10. C. $1336-1340$.

[21] Гурвич Л.В. идр. Энергии разрыва химических связей. Потенциалы ионизации и сродство к электрону. М.: Наука, 1974. $351 \mathrm{c}$. 